\title{
Alveolar permeability in HIV antibody positive patients with Pneumocystis carinii pneumonia
}

\author{
M J O'DOHERTY,* C J PAGE, $\dagger$ C S BRADBEER, $\ddagger$ M SHAHMANESH, \\ A EDWARDS,$\ddagger$ D BARLOW, N T BATEMAN, ${ }^{*}$ D N CROFT $\dagger$
}

From the Department of *Thoracic, $\uparrow N u c l e a r$, and $\ddagger$ Genitourinary Medicine, St Thomas’s Hospital, London

SUMMARY Pulmonary permeability was assessed using the technique of ${ }^{99 \mathrm{~m}} \mathrm{Tc}$ (technetium-99m) diethylene triamene pentacetic acid (DTPA) aerosol transfer in 10 patients who had antibodies to human immunodeficiency virus (HIV) and were non-smokers and in $20 \mathrm{HIV}$ antibody positive smokers. Five patients had Pneumocystis carinii pneumonia (PCP) proved by transbronchial lung biopsy; four were non-smokers and one a smoker.

Two findings emerged: patients with PCP had greater epithelial permeability than non-smokers and smokers; and the permeability curves were monophasic in smokers and non-smokers, but biphasic in patients with PCP.

The biphasic curve observed is indicative of diffuse alveolar damage and might be useful to predict PCP in patients with antibodies to HIV who have normal chest radiographs. As the study was of only five patients with PCP, however, further studies are necessary to confirm this observation.

Pneumocystis carinii is a serious opportunistic pathogen in patients who are immunocompromised, and is the most common organism in pneumonia related to the acquired immune deficiency syndrome (AIDS). In one large study from the United States it accounted for $373 / 441(85 \%)$ of cases of pneumonia in patients with AIDS. ${ }^{1}$

In $5 \%$ to $10 \%$ of patients with proved Pneumocystis carinii pneumonia (PCP) there are no abnormal physical signs and the chest radiograph is normal. Several non-invasive tests have been proposed to investigate these patients, but all have their limitations. The carbon monoxide transfer factor is reduced, but interpretation may be difficult in smokers and intravenous drug abusers. Blood gas measurements may show hypoxaemia, but this is not invariable. ${ }^{23}$ Gallium scanning has a high sensitivity in PCP, but one study showed several false positives. ${ }^{1}$ PCP results in alveolopathy with disruption of the alveolar epithelial interface by destruction of the type 1 pneumocytes, and the resultant increase in lung permeability may be detected using the technique of lung

Address for reprints: Dr M J O'Doherty, Department of Thoracic Medicine, St Thomas's Hospital, London SE1 7EH

Accepted for publication 6 January 1987 diethylene triamene pentacetic acid (DTPA) transfer. DTPA transfer may prove useful in detecting PCP at an early stage while the chest radiograph remains normal $^{45}$ and could be used to locate the most severely affected lung regions before performing biopsy.

We are prospectively studying asymptomatic patients who are HIV antibody positive and comparing these patients with those who have developed PCP and with healthy control subjects.

\section{Patients and methods}

In previous studies we derived an index of alveolar permeability from the rate of transfer of ${ }^{99 \mathrm{~m}} \mathrm{Tc}$ (technetium-99m) DTPA from the air space into the blood. ${ }^{67}$ This measurement is referred to as the T50 or half time of transfer.

Subjects studied were 24 male controls (14 nonsmokers and 10 smokers), 30 patients with HIV infection without chest problems (10 non-smokers and 20 smokers), and five patients (HIV antibody positive) with PCP. The age range for all subjects was 25 to 45 years. None had abused drugs intravenously. Apart from the five patients with PCP (four of whom had diffuse infiltrates on the chest radiograph and one had a normal chest radiograph), no subject had a recent 
history of chest infection or a chest radiograph showing any abnormality. The smokers smoked 10 to 30 cigarettes a day. The method of study was the same in all subjects.

The technique of administration of ${ }^{99 m}$ Tc DTPA and our method of analysis have been described previously. ${ }^{67}$ Supine subjects inhaled an aerosol of ${ }^{99 m}$ Tc DTPA produced by a VENTICIS nebuliser delivery system. The particle size has a mass median aerodynamic diameter of $0.9 \mu \mathrm{m}$ and a geometric standard deviation of $1.5 \mu \mathrm{m}$. The subjects inhaled from the nebuliser for two minutes or until a count rate of 6000 counts/second was obtained within the field of view of the gammacamera. A high sensitivity parallel hole collimator was used to acquire data, which were recorded continuously from the camera by an on line computer and formatted as two views. The first view of $\mathbf{4 0}$ frames of one minute each followed both the gradual removal of ${ }^{99 \mathrm{~m}} \mathrm{Tc}$ DTPA from the lung and the increase of ${ }^{99 \mathrm{~m}} \mathrm{Tc}$ DTPA in the background. The second view of $\mathbf{4 0}$ frames of 30 seconds each had an intravenous bolus of $18.5 \mathrm{MBq}{ }^{99 \mathrm{~m}} \mathrm{Tc}$ DTPA given between the tenth and fifteenth frames to allow a calculation of background activity and a method for its correction, described previously. ${ }^{6}$

For the purposes of analysis, each lung image was divided into thirds, giving upper, middle, and lower regions. Each region was corrected for its own background and ${ }^{99 m}$ Tc decay. From these data, we calculated a half time transfer value (T50). ${ }^{67}$ In the case of biphasic curves, the slow component was stripped away from the fast component before assessing the fast phase half time. We compared variations of regional T50 values between patients using Student's $t$ test and compared variations of T50 in each patient using the paired $t$ test.

\section{Results}

The mean regional T50 values (times given in minutes) for each lung region and each patient group are shown in the table. The smaller times indicate increased permeability.

One patient, who had a normal chest radiograph, underwent transfer studies before the development of PCP, during PCP, and after treatment with high dose co-trimoxazole. The figure shows the curves obtained from this patient before, during, and after PCP.
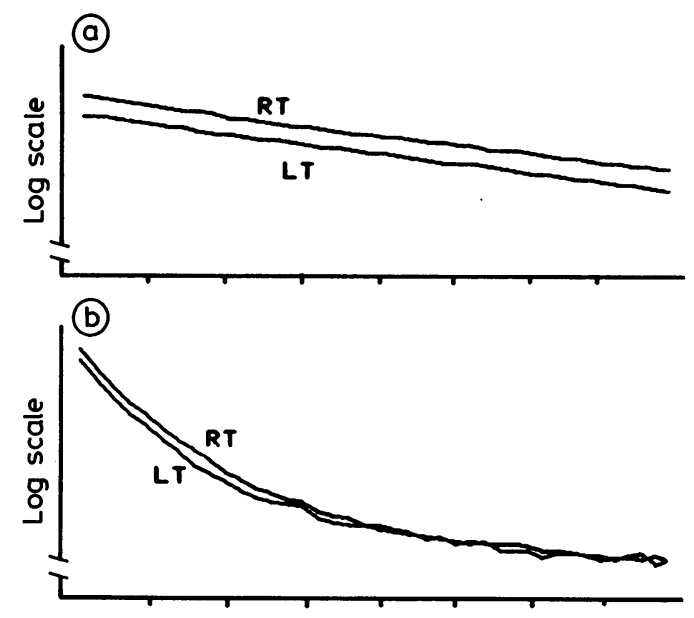

(c)

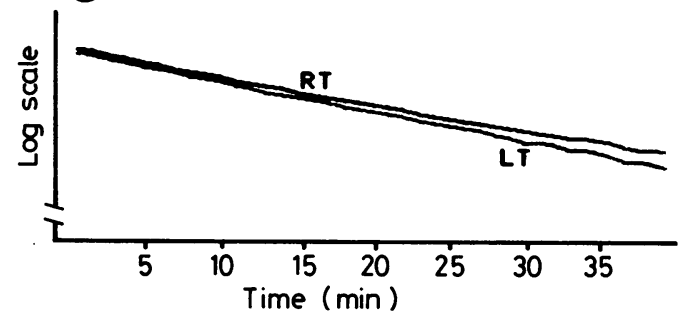

Fig T50 (half transfer time) curves for left and right thorax ( $L T$ and $R T$ ) in a patient with a normal chest radiograph ( $a$ ) before, (b) during, and (c) after infection with Pneumocystis carinii.

Table Diethylene triamene pentacetic acid (DTPA) transfer values (mean T50 (SEM) in minutes) for the three regions of both lungs in all 59 subjects

\begin{tabular}{|c|c|c|c|c|c|c|}
\hline \multirow[b]{2}{*}{ Lung } & \multirow[b]{2}{*}{ Region } & \multicolumn{2}{|l|}{ Control subjects: } & \multicolumn{2}{|c|}{ HIV positive patients: } & \multirow[b]{2}{*}{$\begin{array}{l}\text { With PCP } \\
(n=5)\end{array}$} \\
\hline & & $\begin{array}{l}\text { Non-smokers } \\
(n=14)\end{array}$ & $\begin{array}{l}\text { Smokers } \\
(n=10)\end{array}$ & $\begin{array}{l}\text { Non-smokers } \\
(n=10)\end{array}$ & $\begin{array}{l}\text { Smokers } \\
(n=20)\end{array}$ & \\
\hline $\begin{array}{l}\text { Right } \\
\text { Left } \\
\text { Right } \\
\text { Left } \\
\text { Right } \\
\text { Left }\end{array}$ & $\begin{array}{l}\text { Upper } \\
\text { Upper } \\
\text { Middle } \\
\text { Middle } \\
\text { Lower } \\
\text { Lower }\end{array}$ & $\begin{array}{l}56 \cdot 0(6 \cdot 0) \\
56 \cdot 6(6 \cdot 0) \\
69.0(6 \cdot 4) \\
72 \cdot 0(6 \cdot 1) \\
77 \cdot 5(7 \cdot 0) \\
77 \cdot 0(7 \cdot 1)\end{array}$ & $\begin{array}{l}12.4(1.8) \\
12.4(1.9) \\
19.4(2.8) \\
18.8(2.7) \\
24.5(3.2) \\
23.9(3.5)\end{array}$ & $\begin{array}{l}55 \cdot 0(6 \cdot 7) \\
59 \cdot 8(8 \cdot 2) \\
65.0(8 \cdot 1) \\
67 \cdot 7(9 \cdot 2) \\
64.0(8 \cdot 4) \\
64.0(9 \cdot 5)\end{array}$ & $\begin{array}{l}14.8(1.5) \\
14.2(1.5) \\
17.1(1.7) \\
16.9(1.8) \\
18.0(2.2) \\
17.7(2.2)\end{array}$ & $\begin{array}{l}2.4(0.5) \\
1.5(0.15) \\
2.1(0.2) \\
1.9(0.16) \\
2.0(0.14) \\
2.0(0.19)\end{array}$ \\
\hline
\end{tabular}

HIV = human immunodeficiency virus.

PCP = Pneumocystis carinii pneumonia. 
Comparison of comparable lung regions in different patients showed no appreciable differences between the control non-smokers and HIV antibody positive non-smokers or between control smokers and HIV antibody positive smokers. There were significant differences between smokers and nonsmokers $(p<0.01)$ whether HIV antibody positive or negative.

The correlation coefficient for the exponential least squares fit to the DTPA transfer curves is normally $>0.98$. In patients with PCP the curves were biphasic, and the first phase after curve stripping had correlation coefficients of $>0.99$. The first phase T50 values for each lung region in patients with $\mathrm{PCP}$ were significantly different from those who were HIV antibody positive, both non-smokers $(p<0.002)$ and smokers $(p<0.005)$. Of six HIV antibody positive smokers with transfer times of less than six minutes, none had biphasic curves.

\section{Discussion}

In this study we have demonstrated that pulmonary transfer of ${ }^{99 m}$ Tc DTPA is increased in patients with PCP. This indicates that the pulmonary permeability to small solutes is increased. Not only was this increase in permeability significantly greater in absolute terms than that found in smokers, but the character of the transfer curve was also a multiexponential function. Biphasic curves have been reported previously in hyaline membrane disease. ${ }^{8}$ The inflammatory response and widespread alveolopathy seen in patients with $\mathrm{PCP}^{9}$ represents a patchy destructive process similar to that of hyaline membrane disease. The finding of a biphasic curve probably represents multiple areas of differing transfer or permeability..$^{1011}$

The differences between HIV antibody positive non-smokers and control non-smokers or between HIV antibody positive smokers and control group smokers were not significant, which suggests that the virus itself does not have a specific effect on lung permeability.

Despite the small number of patients with PCP studied, the biphasic curve was present only in this group. A biphasic curve in HIV positive patients cannot be explained by smoking habit. It might therefore be used as a test to reduce the number of patients requiring lung biopsy. Rosso et al and Ketchum have shown that half time clearance values for ${ }^{99 m} \mathrm{Tc}$ DTPA (or lung permeability) were increased (smaller T50 times) even in patients with normal chest radiographs and PCP (provided that they were non- smokers) and that this permeability improves with treatment of the disease. ${ }^{412}$ The problems of distinguishing any change in smoking habit from resolution of PCP remained, however, as the curves in their patients were monophasic. Smoking by itself increases permeability, and stopping decreases permeability. Any test of value therefore has to be useful in HIV positive patients who smoke $(66 \%$ in our study).

We envisage this measurement as an early detection method, even in smokers, which is safe and easy to use. It may lead to early bronchoscopic diagnosis and treatment, and may influence the outcome of PCP. More patients will need to be studied before these questions can be answered.

\section{References}

1 Murray JF, Felton CP, Garay SM, et al. Pulmonary complications of the acquired immunodeficiency syndrome. Report of a national heart, lung and blood institute workshop. $N$ Engl $J$ Med 1984;310:1682-8.

2 Farthing C. Pneumonia in the acquired immune deficiency syndrome. Br Med J 1985;290:1829.

3 Goodman JL, Tashkin DP. Pneumocystis with normal chest Xray film and arterial oxygen tension. Early diagnosis in a patient with acquired immune deficiency syndrome. Arch Intern Med 1983;143:1981-2.

4 Ketchum LE. AIDS diagnosis and monitoring improved by radionuclide procedures. $J$ Nucl $\mathrm{Med}$ 1985;26:1109-12.

5 Mason GR, Duane GB, Effros RM, Mena I. Rapid.clearance of inhaled aerosols of technetium-99m DTPA in patients with Pneumocystis carinii pneumonia. J Nucl Med 1985;26:59 [abstract].

6 O'Doherty MJ, Page CJ, Croft DN, Bateman NT. Lung ${ }^{99 m}$ Tc DTPA transfer: a method for background correction. Nucl Med Commun 1985;6:209-15.

7 O'Doherty MJ, Page CJ, Croft DN, Bateman NT. Regional lung epithelial leakiness in smokers and non-smokers. Nucl Med Commun 1985;6:353-7.

8 Jefferies AL, Coates G, O'Brodovich H. Pulmonary epithelial permeability in hyaline-membrane disease. $N$ Engl $J$ Med 1984;311:1075-80.

9 Anonymous. Pneumocystis-an orphan organism? Lancet 1985; i:676-7[editorial].

10 Jones JG, Minty BD, Beeley JM, Royston D, Crow J, Crossman RF. Pulmonary epithelial permeability is immediately increased after embolisation with oleic acid but not with neutral fat. Thorax 1982;37:169-74.

11 Jefferies AL, Coates G, Webber CE, O'Brodovich H. Measurement of pulmonary clearance of radio aerosol using a portable sodium iodide probe. J Appl Physiol 1984;57:1908-12.

12 Rosso J, Picard C, Mayand C, Revuz J, Meignan M. Comparison of ${ }^{99} \mathrm{~m}$ Tc DTPA aerosol and Gallium scans in early detection of Pneumocystis carinii pneumonia in acquired immune deficiency syndrome. J Nucl Med 1986;27:951 [abstract]. 